\title{
Temporal Bone Osteoma and Dementia
}

Temporal Kemik Osteomu ve Demans

\author{
University of Health Sciences Turkey, Sultan 2. Abdulhamid Han Training and Research Hospital, Clinic of Neurology, Istanbul, Turkey
}

Keywords: Temporal bone osteoma, dementia, radiograph, CT, MRI

Anahtar Kelimeler: Temporal bone osteomu, demans, radyografi, BT, MRG

Dear editor,

An 84-year-old female patient presented with memory impairment. Her son reported that she had delayed recall and progressive decline in cognitive functions more than expected with ageing. However, she did not fulfill the criteria of clinically probable Alzheimer disease. Mental tests revealed delayed recall and mildly impaired near-memory. The patient had a history of diabetes mellitus, hypertension and coronary artery disease. Stents were placed in her coronary arteries 4 years ago. Medical history and examination of the patient revealed that the onset of memory impairment was approximately one year before and deteriorated thereafter. Patient was recently unable to recognize the neighborhood she lived in, but her daily living activities were mostly preserved. The mini-mental state exam score was 15/30. She had no other remarkable neuropsychological findings. Cranial magnetic resonance imaging study revealed a non-enhancing calcified mass lesion with a diameter of $2.5 \mathrm{~cm}$ that seemed to originate from the internal table of the left temporal basal calvarium. There were no signs of hydrocephalus or unproportionate cerebral cortical atrophy. Uncus and parahippocampal gyrus on the left side were pushed medially (Figure 1). Computerized tomography scan confirmed an osteoma of the osseous density of $28 \times 22 \mathrm{~mm}$ that merged with the internal table (Figure 2). Plain radiographs of the skull in antero-posterior and lateral positions also discerned the osseous lesion (Figure 3).

Neuroimaging findings are important for clinical evaluation of dementia. Collecting and integrating structural neuroradiological findings may confirm neurodegenerative disease symptoms (1). Combining different modalities in imaging can provide

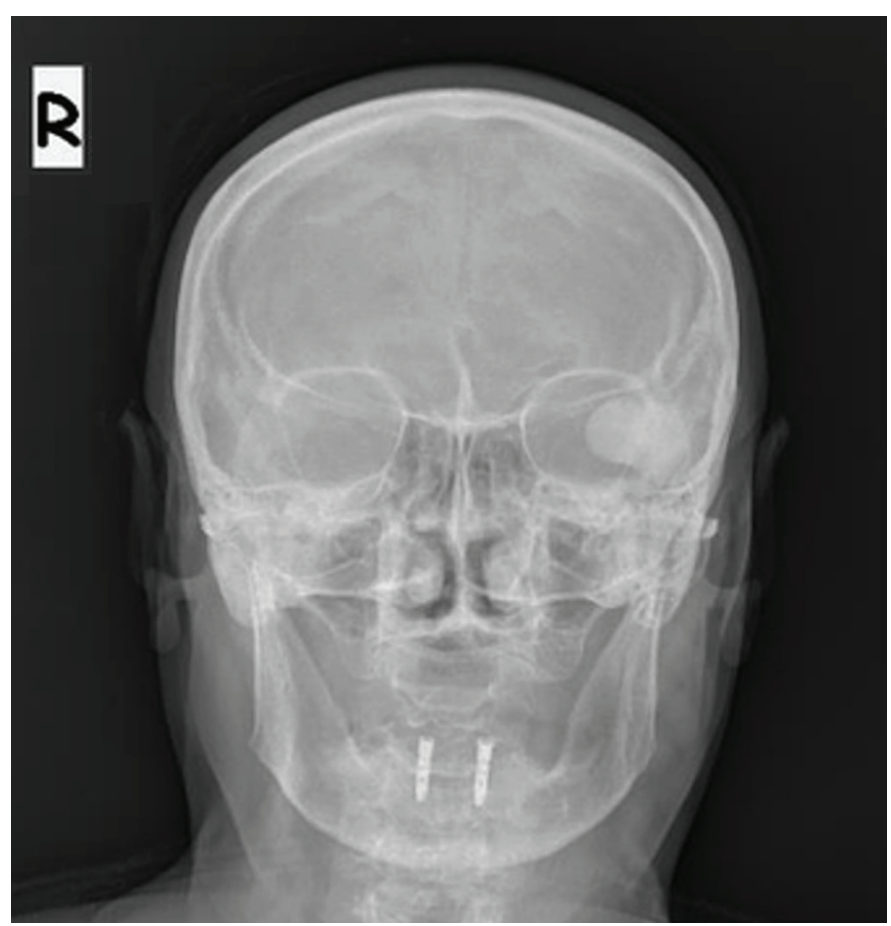

Figure 1. Lateral radiograph of the skull: an ossific nodule, wellcircumscribed $3 \times 5 \mathrm{~cm}$ sized lesion within the left temporal bone

complementary information that further details underlying structural brain changes. This is of crucial importance to elucidate

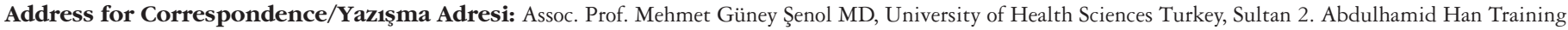
and Research Hospital, Clinic of Neurology, Istanbul, Turkey

Phone: +902165422020 - 3803 E-mail: mgsenol@yahoo.com ORCID: orcid.org/0000-0001-6397-9293

Received/Geliş Tarihi: 19.01.2020 Accepted/Kabul Tarihi: 10.12.2021

${ }^{\circ}$ Copyright 2022 by Turkish Neurological Society

Turkish Journal of Neurology published by Galenos Publishing House. 
emerging functional brain impairments and thereby enabling a superior diagnosis.

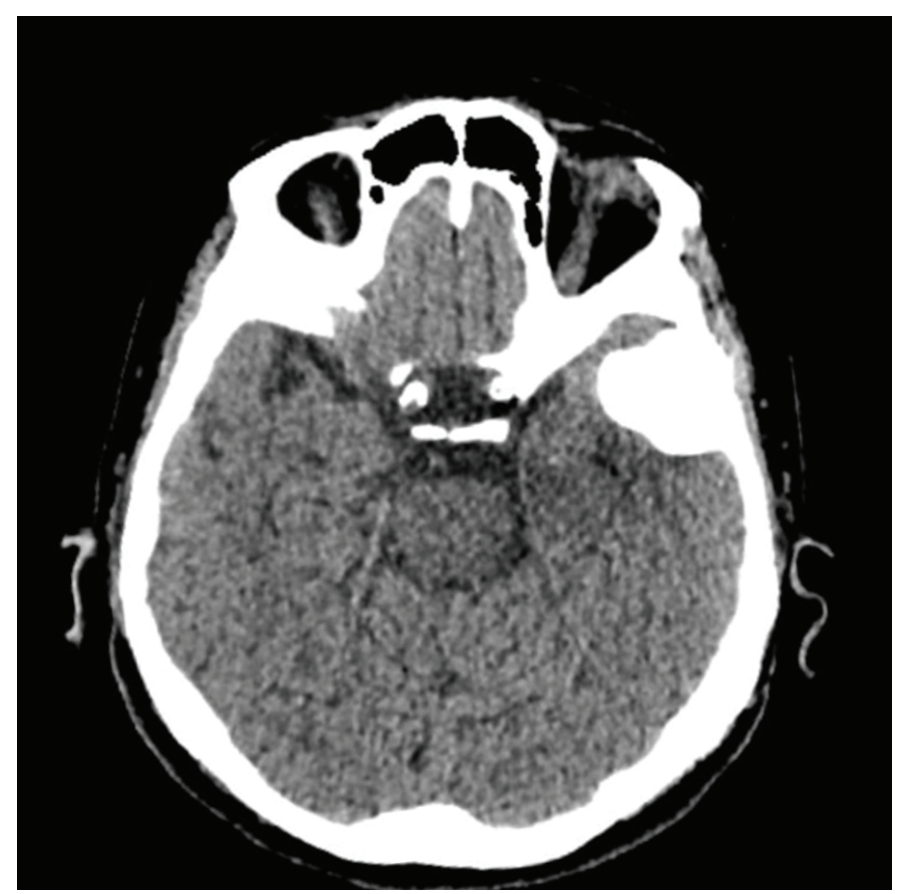

Figure 2. Computed tomography imaging revealed a homogeneously solid calcification in the left temporal area

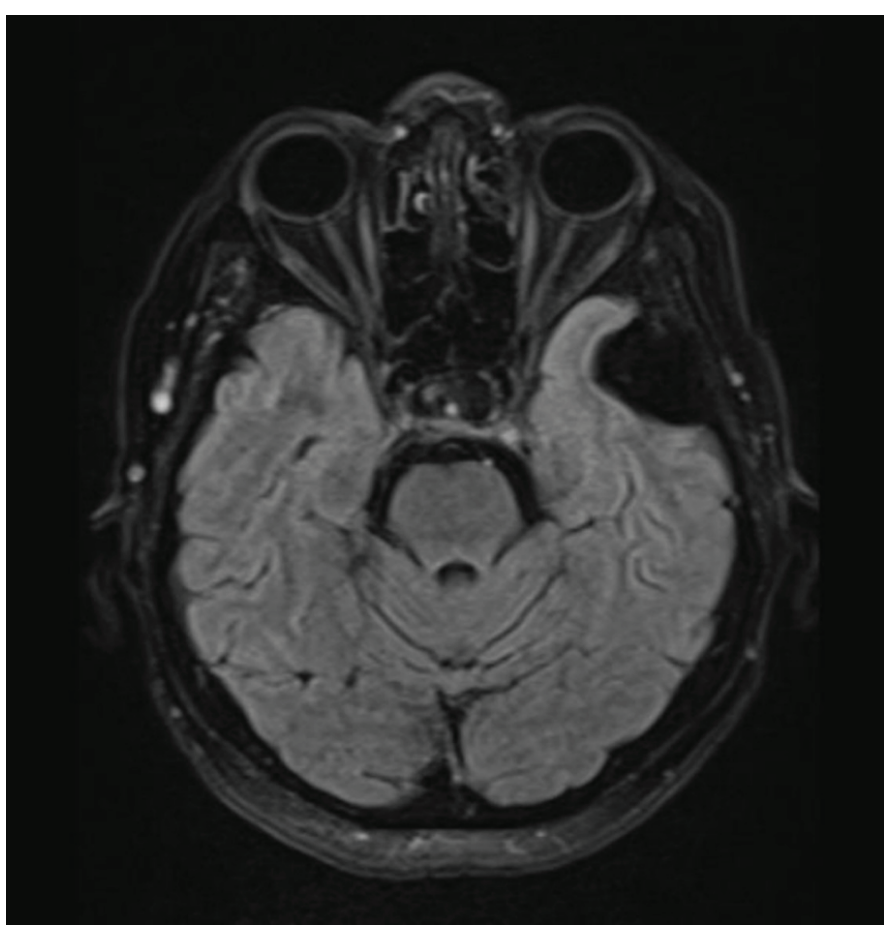

Figure 3. The FLAIR MRI sequence showed an area of signal loss in the left temporal lobe

MRI: Magnetic resonance imaging, FLAIR: Fluid-attenuated inversion recovery

\section{Ethics}

Informed Consent: Written consent was obtained.

Peer-review: Externally and internally peer-reviewed.

Authorship Contributions

Surgical and Medical Practices: M.G.Ş., H.Ş., Concept: M.G.Ş., Design: M.G.Ş., Data Collection or Processing: M.G.Ş., Analysis or Interpretation: M.G.Ş., H.Ş., Literature Search: M.G.Ş., Writing: M.G.Ş., H.Ş.

Conflict of Interest: No conflict of interest was declared by the authors.

Financial Disclosure: The authors declared that this study received no financial support.

\section{Reference}

1. Barajas RF Jr, Perry A, Sughrue M, Aghi M, Cha S. Intracranial subdural osteoma: a rare benign tumor that can be differentiated from other calcified intracranial lesions utilizing MR imaging. J Neuroradiol 2012;39:263-266. 